QUADERNS DE FILOSOFIA VOL. VII NÚM. 2 (2020): 37-57

EISSN: 234I-3042 DOI: I 0.7203/QFIA. 7.2.I 8803

DAVID SÁNCHEZ USANOS

Universidad Autónoma de Madrid

\title{
Modo supervivencia: sobre la despolitización del imaginario contemporáneo (utopía y distopía)
}

Survival mode: on the depoliticization of the contemporary imaginary (utopia and dystopia)

Recibido: 6/10/2020. Aceptado: 16/12/2020

Resumen: En este artículo analizamos el actual estatuto de la utopía y de la distopía a partir de los cambios en la experiencia y la sensibilidad acontecidos en la postmodernidad-globalización. Reflexionaremos sobre la forma en la que experimentamos el tiempo y el cambio histórico y acerca del modo en el que la realidad aparece representada en los productos culturales contemporáneos. En este sentido, nos fijaremos en lo que hemos denominado la "privatización de la utopía" a propósito del descrédito de la política y de los proyectos colectivos, y atenderemos tanto a la conciencia de un final que parece haberse instalado en nosotros desde hace tiempo como a sus posibles antecedentes.

Abstract: We will analyze the present role and concept of utopia and dystopia in connection with the changes in our experience and sensibility that have taken place under postmodernity-globalization. We will think about our time and historical change experience and about the way reality is represented in contemporary cultural products. We will pay attention to what we call "the privatization of utopia" regarding the discredit of the political and collective projects and we will also consider the consciousness of an ending (and their possible antecedents) that seems to be settled in us for quite some time.

Palabras clave: utopía, distopía, Fredric Jameson, Northrop Frye, George Orwell, Ricardo Piglia, privatización de la utopía, postmodernidad, globalización, experiencia del tiempo. 
Keywords: utopia, dystopia, Fredric Jameson, Northrop Frye, George Orwell, Ricardo Piglia, privatization of utopia, postmodernity, globalization, time experience.

\section{UTOPÍA, CULTURA Y POSTMODERNIDAD}

D ARtiremos de una hipótesis que no parece demasiado exigente: podemos 1 formular conjeturas legítimas acerca de lo que pensamos a partir de lo que decimos. Podemos hacerlo, además, sin atenernos estrictamente al contexto de enunciación; por ejemplo, pensamos que puede tener sentido buscar en obras literarias, artísticas o filosóficas —en los productos culturales, en definitivaelementos que permitan reconstruir el imaginario político o existencial de determinado momento histórico, concretamente el nuestro. Con esto somos conscientes de no estar inventando nada. Pretendemos situarnos en una larga tradición interpretativa que, para la cuestión que nos ocupa, tiene en Reification and Utopia in Mass Culture (Jameson i979) uno de sus momentos culminantes. En ese artículo, Fredric Jameson analiza la forma en que la cultura de masas (películas como Tiburón o la saga de El Padrino) cumple una función ideológicamente legitimadora del orden social, pero también cómo conecta con el impulso utópico presente en el inconsciente político de su audiencia. De ese modo, las obras citadas reflejarían, por una parte, la sociedad existente y, por otra, estrategias de redención u oposición a los factores más característicos y hostiles de esa misma sociedad (por ejemplo, frente al capitalismo ubicuo e impersonal el trabajo cooperativo en Tiburón y los valores de la familia en El Padrino). Es por ello que su naturaleza sería necesariamente dialéctica, conflictiva. ${ }^{1}$ A este respecto hay que mencionar al filósofo marxista Ernst Bloch, antecedente de la posición de Jameson que consideraba que en el ser humano existe un impulso utópico constante susceptible de detectarse en toda manifestación artística y cultural a modo de "excedente". ${ }^{2}$

La conexión entre utopía y pensamiento político se establece desde los orígenes del término merced a la obra de Moro de 1516, pero en el pasado reciente fue proscrita por su supuesta asociación con los regímenes totalitarios. Para algunos, el adjetivo "utópico" tenía - y sigue teniendo- una connotación peyorativa que lo asimila a "ingenuo" o "romántico", y sobre todo a "estalinista". Se trata de un asunto que el propio Jameson ha examinado ampliamente; ${ }^{3} \mathrm{de}$ hecho, la cuestión de la utopía ocupa el lugar central de su planteamiento,

${ }^{1}$ Véase también Jameson (198I).

${ }^{2}$ Agradezco mucho a Francisco Martorell esta precisión, así como su atenta lectura de una versión preliminar de este texto.

${ }^{3}$ Véase, por ejemplo, Jameson (I994; 2004; 2005). 
dedicado a relacionar la capacidad imaginativa - explorada a partir de propuestas artísticas y culturales - con la posibilidad del cambio político. En este sentido, cabe recordar que suya es la frase más citada en relación con la crisis de la utopía y la proliferación de distopías, ésa que afirma que nos resulta más sencillo imaginar el fin del mundo que el fin del capitalismo. ${ }^{4}$ En efecto, generamos sin cesar ficciones que representan el fin del mundo - o de la propia especie humana - por falta de petróleo, por falta o exceso de agua, por el impacto de meteoritos, por algún tipo de virus o catástrofe climática, por el resurgir de los dinosaurios o por la rebelión de tecnologías que cobran vida propia. En cambio, nos resulta mucho más complicado pensar en películas, relatos o series que representen modos de vida radicalmente alternativos al nuestro, en los que el modelo de sociedad que se plantee no sea un trasunto del modo de producción capitalista, reproduciendo la misma división del trabajo y el mismo esquema de propiedad privada y relaciones jerárquicas que conocemos sobradamente (estén o no camulladas con ropajes exóticos o ambientadas en otro tiempo y lugar). Las dificultades para pensar mundos distintos desde el punto de vista literario o artístico concuerdan con el tono emocional de resignación política generalizada que caracteriza la contemporaneidad. Ello hace que, casi inevitablemente, terminemos leyendo entre interrogantes el conocido lema de «Otro mundo es posible». ¿Qué ha pasado con nuestros sueños?, ¿se ha desvanecido el impulso utópico?, ¿cuál es ahora nuestro ideal regulativo?

\section{LA ESPACIALIZACiÓN DEL TIEMPO, EL BLOQUEO DE LA IMAGINACiÓN Y LA LITERATURA DE ANTICIPACIÓN}

Estas cuestiones están invariablemente determinadas por la conciencia del tiempo. Una de las notas que caracteriza el presente es lo que Jameson denominó "la pérdida de sentido histórico": el hecho de que habitemos en un presente perpetuo donde el pasado se parece a un repositorio de imágenes y motivos donde se mezclan lo real y lo ficticio, al que se recurre con propósitos estéticos o mercantiles y en el que el futuro como tal se ha desvanecido, siendo como somos incapaces de imaginar futuros que no supongan la mera prolongación

\footnotetext{
${ }^{4}$ La cita no es exactamente así, sino que reza "It seems to be easier for us today to imagine the thoroughgoing deterioration of the earth and of nature than the breakdown of late capitalism; perhaps that is due to some weakness in our imaginations" (JAMESON 1994, xii, "Parece que hoy nos resulta más sencillo imaginar el deterioro absoluto de la tierra y de la naturaleza que el derrumbe del capitalismo avanzado; quizá ello se deba a cierta debilidad de nuestra imaginación"; la traducción es nuestra). Posteriormente, Jameson (2003A) retoma esa misma idea y contribuye a su actual formulación. Sobre el destino de la frase véase el comienzo de Beaumont (2014).

${ }^{5}$ Véase Martorell (2019).
} 
del momento actual (salvo en el aspecto tecnológico, donde sí contemplamos margen para el cambio y la modernización). Nos movemos dentro de un mundo globalizado y uniforme que supone la consumación del modo de producción capitalista, una estructura que somos incapaces de representar y que, en lugar de asociarla a procesos históricos en los que hemos intervenido (y que, por tanto, la harían virtualmente modificable), la experimentamos a la manera de un fenómeno meteorológico frente al que solo cabe reaccionar e intentar adaptarnos. Este bloqueo colectivo ante la consolidación de la postmodernidad y de la globalización se traduce en desórdenes afectivos individuales ${ }^{6}$ y en la alteración de los patrones espacio-temporales. Según Jameson, la experiencia presente se rige más por parámetros espaciales que temporales, ${ }^{7}$ lance que da lugar al "fin de la temporalidad" y que se refleja también, enseguida lo certificaremos, en el particular destino de la utopía.

Aunque pueda resultar paradójico en función del diagnóstico recién enunciado, lo cierto es que la utopía abandonó el significado espacial que poseyó en su origen (la isla de Moro y otros enclaves similares) para adquirir una denotación temporal (detalle detectado por autores como John Bury o H. G. Wells). En efecto, en un mundo absolutamente cartografiado, la utopía pasó a significar más un proyecto colectivo a desarrollar en el tiempo que una localización exótica en la que un grupo social se guiase por pautas esencialmente distintas a las nuestras (y deseables). Esa variación semántica quizá debería habernos llevado a emplear un término distinto, algo que pareció sugerir sin demasiado éxito Umberto Eco, siempre comprometido con el matiz y la precisión lingüística.

En 1984, ${ }^{9}$ el mismo año en el que Jameson publica su famosísimo artículo sobre el postmodernismo, el escritor italiano, en Los mundos de la ciencia-ficción, aborda la oposición entre literatura realista y literatura fantástica tomando como referencia el tipo de mundo que ambas plantean, sobre el que se desarrollan la trama y los personajes. La literatura realista supone un mundo equivalente al nuestro, mientras que la fantástica propone otro estructuralmente diferente en función de la siguiente clasificación:

\footnotetext{
${ }^{6}$ Véase Jameson (I984 y 2003B); no obstante, consideramos que la experiencia del tiempo en la postmodernidad es una de las claves a partir de las cuales se articula el pensamiento de Jameson, algo que desarrollamos en Sánchez Usanos (2010; 2020). También podría atenderse a toda una tradición de pensamiento germánico, de Reinhardt Koselleck a Harmut Rosa, que aporta un utillaje conceptual y diagnóstico muy pertinente para el presente artículo a propósito de la clausura de la realidad y de la experiencia o la aceleración del tiempo y su conexión con la enajenación. Por cuestiones de espacio no podemos llevar a cabo aquí ese desarrollo, pero remitimos al lector interesado a Koselleck (2007A y 2007B), Rosa (2016) y Sánchez Usanos (2012).

${ }^{7}$ Véase Jameson (1984) y Sánchez Usanos (2010).

${ }^{8}$ Véase Jameson (2003B).

${ }^{9}$ La referencia a George Orwell también parece inevitable.
} 
-Alotopías: describen un mundo distinto del real (con animales que hablan o seres fabulosos como las hadas y magos) y pretenden que el lector lo acabe considerando más real que el real (una forma de escapismo).

-Utopía: habla de un mundo posible paralelo al nuestro y quizá inaccesible. Puede tener un sentido proyectivo (representación de una sociedad ideal), como en el caso de Tomás Moro, o caricaturesco, como en el de Jonathan Swift (deformación irónica de la realidad). Según Eco, esta variante tendría siempre una intención exhortativa o preceptiva.

-Ucronía: el mundo paralelo que nos presenta se construye sobrela premisa de una variante de un hecho histórico conocido; se trata de una propuesta literaria hipotética y más o menos verosímil a partir de un contrafáctico, caso de El hombre en el castillo (1962), de Philip K. Dick, novela que transcurre en los Estados Unidos bajo el supuesto de que los nazis vencieron en la Segunda Guerra Mundial. ${ }^{10}$

-Metatopía y metacronía: el mundo posible que se plantea en estas variantes genéricas es distinto del real pero verosímilmente alcanzable en virtud de las posibilidades tecnológicas y políticas contenidas en el presente en forma tendencial. "Definiremos este tipo de literatura fantástica como novela de anticipación y utilizaremos esta noción para definir de modo más correcto la ciencia-ficción" (ECO 1984, 222).

En el caso de aceptar el catálogo de Eco, creo que "metacronía" sería el término más adecuado para referirnos al sentido contemporáneo que tiene para nosotros la utopía. Al igual que sucede con "utopía" —etimológicamente "no-lugar", como mucho "lugar imaginario", pero no necesariamente bueno o deseable, ${ }^{11}$ aunque lo descrito por el libro de Moro titulado así pueda serlo para algunos-, en principio tampoco "metacronía" es un término cargado moralmente, por lo que "distopía" o "discronía" no serían estrictamente antónimos de "utopía" y "metracronía" respectivamente, sino variantes lexicales que apuntan a un campo semántico común, pero restringido a lo indeseable o pesadillesco. No obstante, dada su implantación seguiremos usando los términos "utopía" y "distopía" en el sentido habitual. Más interesante resulta el carácter temporal señalado por Eco cuando define la ciencia-ficción como la variante literaria de la metacronía y habla de "novela de anticipación", subgénero de la literatura fantástica que proyecta escenarios del porvenir susceptibles de ser alcanzados, dotados, por tanto, de cierto grado de verosimilitud. En su descripción de la ciencia-ficción, Eco repara, asimismo, en el carácter moralista

${ }^{10}$ En una línea parecida se mueven películas como Inglorious basterds o el final de Once upon a time in Hollywood de Quentin Tarantino o, desde un punto de vista metanarrativo, la legendaria colección de Marvel What if...?

${ }^{11}$ Acerca de esta cuestión véase Curry (2007), Carey (2000) y, a propósito del posible tono irónico-satírico-burlesco de la obra de Moro, Atwood (2007) y Sánchez (201 I). 
y distópico que necesariamente tiene el género: "El autor de ciencia-ficción es simplemente un científico imprudente y muchas veces lo es por severas razones morales (sobre todo cuando conjetura sobre los fenómenos sociales), porque, al prever y anunciar un futuro posible, lo que quiere en realidad es prevenirlo" (ECO I984, 227).

Nos encontramos con la paradoja de que un término originalmente espacial acabó teniendo un significado eminentemente temporal, alteración en la que sin duda influyó la intensificación de la experiencia histórica del tiempo acontecida durante la modernidad y el conocimiento exhaustivo de la totalidad del globo. Como veremos, con el declinar de ese modo de experimentar el tiempo y el desfondamiento de la idea misma de pertenencia social, la utopía acabó por recodificarse en clave personal, ajustándose así a la forma de gestionar la experiencia en la postmodernidad que comentamos arriba.

Si seguimos a Frye, la ciencia-ficción sería la variante de la literatura utópica caracterizada por proyectar en el tiempo determinadas tendencias sociales y tecnológicas del presente:

La mayoría de los escritores utópicos siguen, bien a Moro (y a Platón), al acentuar la estructura legal de sus sociedades, o bien a Bacon, al acentuar su poder tecnológico. Aquel tipo de utopía está más cerca de la verdadera teoría política y social; este último se solapa con lo que ahora se llama ciencia-ficción. Naturalmente, desde la Revolución Industrial ninguna utopía seria puede evitar el introducir temas tecnológicos. Y puesto que la tecnología es progresiva, el camino de la utopía ha tendido crecientemente a ser más bien un viaje en el tiempo que en el espacio, una visión del futuro y no de una sociedad localizada en algún punto aislado del globo (FrYe 1982, 58)

Otro factor que subraya Frye es que la ciencia-ficción, o cualquier forma de literatura de anticipación, contiene una hipótesis ontológica acerca del funcionamiento de la sociedad y, por tanto, expectativas acerca de las posibilidades y la conveniencia del cambio social (aunque estos aspectos no tienen por qué plantearse de modo explícito en el texto ni, desde luego, formar parte de las intenciones del autor).

La ciencia y la tecnología —especialmente la última—introducen en la sociedad la concepción de un cambio social dirigido, cambio con unas consecuencias lógicas unidas a él. Estas consecuencias ponen en funcionamiento el aumento de hábitos rituales. Y en tanto en cuanto un hábito ritual puede verse todavía como una posibilidad inminente, como algo que podemos o no podemos adquirir, puede producirse una actitud emocional frente a él, bien de aceptación o bien de rechazo (FrYe 1982, 58) 
Para Frye, uno de los rasgos definitorios de las utopías literarias converge con el carácter global, uniforme y anónimo de la experiencia postmoderna, y más en concreto con un miedo expresado también en términos espaciales: "Una cierta dosis de claustrofobia penetra en este argumento cuando se constata, como ocurre desde aproximadamente 1850 en adelante, que la tecnología tiende a unificar el mundo entero. La concepción de una utopía aislada, como la de Moro, o la de Platón, o la de Bacon, se va evaporando gradualmente en presencia de este hecho" (FrYe i982, 59).

De todo ello se sigue que la ficción de anticipación plantea conjeturas acerca del modo de funcionamiento efectivo de la sociedad de la que emana, por lo que, en este sentido, la distinción establecida por Umberto Eco entre literatura realista y literatura fantástica no parece tan nítida en la actualidad, especialmente en lo relativo a la ciencia-ficción. De hecho, ésta última podría considerarse una variante - exagerada, si se quiere - de la literatura realista, toda vez que su eficacia simbólica depende, en buena medida, de lo verosímil que resulte su propuesta. Paralelamente, lo vimos al comienzo, las propuestas artísticas y culturales más convencionalmente realistas también contienen elementos anticipatorios o utópicos. En consecuencia, la utopía y la ficción de anticipación se asemejan más a una clave de lectura u horizonte interpretativo que a géneros rígidos de escritura. ${ }^{12}$

\section{El mundo clausurado, el desmantelamiento de lo colectivo Y LA PRIVATIZACIÓN DE LA UTOPÍA ${ }^{13}$}

El mundo y la naturaleza invitan a ser interpretados en virtud de modelos o categorías que los hagan más comprensibles, que nos permitan establecer

12 Algo especialmente significativo en nuestros días, en los que la propia frontera entre realidad y ficción parece diluirse como nunca antes. A este respecto, nos permitimos citar la sugerente observación de Ramón del Castillo vertida en la última edición del Festival Eñe:

[...] me he dado cuenta de que estoy dejando de leer utopías o distopías filosóficas y es porque leo más periodismo, frente al cual la ciencia-ficción se ha quedado muy corta. El periodismo de investigación es la verdadera política-ficción. [...] Los periodistas son los nuevos realistas sucios, dicho en el mejor sentido de la palabra sucio. En la ciencia-ficción había una estilización y una moraleja o mensajes edificantes, mientras que cuando algunos periodistas te dicen que el mundo es un sumidero de mierda no son nada edificantes. [...] Cuesta creer cosas que están pasando en nuestro mundo, historias que parecen salidas de un cuento de Ballard, pero que resulta que, comparado con las historias a las que nos ha acostumbrado el periodismo comprometido, Ballard parece un romántico cursi del siglo XIX (Arjona, del Castillo, García Aller y Martín 2020, 32).

${ }^{13}$ Con posterioridad a la redacción de este artículo he tenido noticia de un volumen colectivo dedicado al pensamiento de Ernst Bloch titulado The privatization of hope. Ernst Bloch and the Future of Utopia cuyo título no puedo considerar más afín a algunas de las tesis que se defienden aquí. 
predicciones e intervenir en ellos. No es infrecuente, de hecho, que la realidad misma sea descrita en términos literarios, como actualmente sucede a propósito del adjetivo "distópico": ya no vivimos días "extraños" sino "distópicos", calificativo que a veces parece ser una variante de "surrealistas" o "kafkianos" (y que en cierto modo nos informa de la crisis de representación de la realidad a la que aludíamos, de la insuficiencia de los modelos que tratan de explicar la realidad en función de patrones racionales proponiendo la continuidad de la especie humana y/o la del propio planeta). Y quizá a propósito de Kafka y de las lecturas que propicia encontremos alguna clave adicional para nuestro análisis. Al decir de Kundera, Kafka fue uno de los primeros en constatar la unidad efectiva del mundo, pero esa unidad no se habría producido al modo del sueño cosmopolita de la Ilustración, sino que habría adoptado formas desasosegantes. A partir de Kafka, en la historia de la literatura el mundo deja de ser un escenario de aventura y descubrimiento y pasa a ser descrito como una trampa amenazante de la que solo cabe protegerse o intentar huir, posibilidad que Kafka parece cancelar: "la unidad de la humanidad significa: nadie puede escapar a ninguna parte" (Kundera 20 I2, 22). Si, como hemos sugerido, la utopía es más una clave de lectura que un género en sentido estricto, las figuras o motivos utópicos más recurrentes en Kafka no tendrían que ver con ningún proyecto de carácter colectivo, sino con el deseo de fuga individual, opción palpable en sus Diarios y en la celebrada pieza Ordené traer mi caballo del establo...

“¿Adónde cabalgas, señor?”. "No lo sé”, dije, "lejos de aquí, lejos de aquí. Siempre lejos de aquí, solo así podré llegar a mi meta”. “¿Así que conoces tu meta?”, preguntó. "Sî", respondí, "acabo de decirlo, 'Lejos-de-aquî", ésa es mi meta" (KAFKA I922, 257)

De este modo, constatamos que "distopía” y "utopía” forman a menudo un par dialéctico, una díada que permite aventurar que en Kafka la realidad el mundo - se presenta de forma distópica, y que el correspondiente impulso utópico se materializa en un deseo de huida expresado en clave individual y quimérica.

Uno de los rasgos definitorios de la postmodernidad-globalización ya consolidada, de esta época de la que parece que no se puede escapar, fue lo que Lyotard llamó "la desaparición de los grandes relatos —o metarrelatos-", la pérdida de vigencia y legitimidad de los paradigmas que, como el comunismo, el cristianismo o la Ilustración, articulaban la experiencia colectiva, dotaban de sentido a la acción y ofrecían expectativas de realidades distintas. "La muerte de los grandes relatos" podría describirse también como la desactivación de la 
utopía, al menos desde un punto de vista colectivo, social. La utopía quedó desacreditada o restringida al plano estrictamente individual.

Ricardo Piglia ilustra esta privatización de la utopía, tanto en sus lúcidos análisis literarios como en su testimonio vital y político. En el tercer volumen de Los diarios de Emilio Renzi, acuña, refiriéndose a una antología de relatos de ciencia-ficción, una fórmula muy relevante para las cuestiones que aquí nos ocupan:

Últimamente han aparecido lo que podríamos llamar las utopías defensivas. ¿Cómo podemos escapar del control? Una estrategia de huida imposible, porque no hay lugar de llegada. Hace unos meses hicimos una antología en Buenos Aires y les pedimos a veinte narradores de distintas generaciones que escribieran un relato situado en el futuro. Los textos, más que apocalípticos, eran ficciones defensivas definidas por la soledad y la fuga. Son utopías que tienden a la invisibilidad, intentan producir un sujeto fuera de control (Piglia 20 I7, 261)

La soledad y la fuga - elementos muy presentes también en la narrativa de Kafka- son aspectos muy reconocibles a la hora de analizar nuestra experiencia. La utopía muta en defensiva, deja de estar vinculada a proyectos colectivos y queda adscrita a ejercicios individuales de supervivencia o retiro. Se trata de una transición que el propio Piglia termina llevando a cabo, pues, aunque concibe que siempre hay un fondo utópico en toda propuesta literaria, y a pesar de su posicionamiento público a favor de la utopía y de la revolución, acaba decantándose por la literatura como una forma privada de la utopía (Piglia 200 I, 94-5), algo que desactiva su carácter político ${ }^{14}$ en favor de la dimensión "estético-existencial":

\section{Lunes}

Utopía privada: vivir sin obligaciones, escribir por obligación (esa es para mí la fórmula de la felicidad). Tentado por las seducciones del hombre que vive solo y aislado, tengo sin embargo que obligarme a la socialización (PIGLia 2017, 124-5)

¿En qué se traduce la combinación donde concurren la desaparición del sentido histórico, la sensación de habitar un presente perpetuo, el individualismo resignado y el desmantelamiento de cualquier relato colectivo que tenga que ver con lo soteriológico o con la posibilidad de emancipación política? El mundo que plantea buena parte de la ficción contemporánea se identifica con una amenaza en la que los otros, remedando la conocida frase de Sartre, son el infierno,

${ }^{14}$ Ya desde Aristóteles sabemos que la política tiene que ver con la vida en común, con la gestión del conflicto colectivo inherente a la vida en sociedad. 
una masa anónima cuya voluntad se encuentra programada (el apogeo de todo lo que tiene que ver con lo zombi se puede leer en función de estos parámetros). Los protagonistas de muchas de estas historias son individuos aislados que conocen algún tipo de clave, que dudan y se enfrentan al consenso establecido, o, a lo sumo, pequeñas unidades de resistentes frente a la amenazante realidad global. Eso cuando cabe hablar de protagonista o protagonistas, pues, en no pocas ocasiones, se trata simplemente de espectadores - testigos delegados del lector o del espectador de la propia obra-, de pretextos narrativos que vehiculan la descripción minuciosa del mundo y de la red de relaciones propuestos en esa obra de anticipación. Sucede entonces que, a menudo, el interés y la eficacia simbólica de la obra reside antes en la exposición de esa ontología hipotética que en las tribulaciones de los personajes que circulan por ella (que, como ocurre en algunas series, ni siquiera son los mismos de unos episodios a otros).

\section{LA “MODA DisTOPÍA” Y EL FINAL DEL SUEÑO}

Examinaremos a continuación si la ficción de anticipación se ha vuelto más pesimista en la actualidad, si la aparente proliferación de utopías negativas o distopías es un fenómeno radicalmente nuevo y si, en su caso, existen antecedentes.

La obra de J. G. Ballard rebosa de iluminaciones anticipatorias, entre ellas el carácter alucinatorio, dramatizado y heteróclito de la experiencia contemporánea planteada en La exhibición de atrocidades (1969), sin olvidar El espectáculo de televisión más grande del mundo (1972), donde los viajes temporales permiten que el pasado y la historia se mercantilicen y televisen de modo descarnado, o El parque temático más grande del mundo (1989), descripción de una Europa convertida en gigantesco complejo turístico. Estas obras enlazan con Network, un mundo implacable (1976), de Sydney Lumet, la saga de películas Mad Max (1979-201 5) o series más recientes, de Black Mirror (20 I I-2019) a Years \& Years (2019), productos que podrían catalogarse como distopías pero que más bien parecen ser una versión extrema de propuestas realistas, algo que las aproxima a lo grotesco o a la sátira y que, en todo caso, suponen una peculiar puesta en escena del fatídico lema de Margaret Thatcher: "No hay alternativa". ${ }^{15}$

A partir de estos y otros ejemplos similares que el lector puede tener en mente, ¿podría decirse que la distopía o lo distópico se han convertido en un fenómeno de masas? Es más, ¿la sensibilidad a la que apunta este fenómeno es exclusivamente contemporánea o postmoderna? El primer cuento de Ballard, Prima Belladonna, apareció en 1956, pero la fama le llegó más tarde, gracias, en buena medida, a las adaptaciones cinematográficas de algunas de sus obras.

\footnotetext{
${ }^{15}$ Véase Fisher (2016).
} 
Dos décadas después de aquel cuento primigenio, irrumpía en el panorama musical una banda que sí fue famosa, influyente y tremendamente popular desde el principio: los Sex Pistols, que en la canción "God save the Queen", del álbum Nevermind the bollocks. Here's the Sex Pistols (1977), reiteraban que "no hay futuro" (un no future que se convirtió en consigna punk), que cantaban al nihilismo en "Anarchy in the U.K.", que se burlaban del sueño burgués de las vacaciones de verano y hablaban de la claustrofobia y la paranoia contemporáneas en "Holidays in the Sun" y de la falta de sentido en "Pretty Vacant". Sin salir del punk, antes de los Sex Pistols ya The Stooges habían cantado a la falta de horizonte en la composición que abría su álbum de debut («1969»):

Well it's 1969 okay
All across the USA
It's another year
For me and you
Another year
With nothing to do

Entre un disco y otro, en 1971 The Who cerraban el álbum Who's next con "Won't get fooled again" ("No volveremos a ser engańados"), tema en el que se reniega de los resultados políticos de las revoluciones y se expresa la sensación de manipulación que sienten quienes participan en ellas cuando ven que la historia permanece al final inalterable, que su vida cotidiana no mejora, que las nuevas constituciones se parecen sospechosamente a las antiguas y que los eslóganes, líderes y partidos de ambos bandos se suceden en una alternancia "lampedusiana". Frente a ello, a modo de conclusión, la voz narrativa de la canción opta por sonreír y canalizar la antigua energía dedicada a lo político hacia la música, en una nueva versión de esa privatización de la utopía que hemos mencionado:

I'll tip my hat to the new constitution

Take a bow for the new revolution

Smile and grin at the change all around

Pick up my guitar and play

Just like yesterday

Then I'll get on my knees and pray

We don't get fooled again

Don't get fooled again, no, no

Yeah

Meet the new boss

Same as the old boss 
Resulta tentador situar a finales de los sesenta la constatación popular de la imposibilidad de la utopía colectiva, algo que se muestra de modo emblemático en las últimas escenas de Easy Rider (1969), película donde la anagnórisis de los protagonistas de que la América que recorren ya no responde a las coordenadas basadas en la libertad y la aventura se ve puntuada de manera arbitraria y fatídica. En el ámbito de las artes plásticas, la serie de obras Death and Disaster (19631964) de Andy Warhol reproducía y manipulaba imágenes de accidentes de aviones, coches y suicidios, dando pie a posiciones estético-políticas no exentas de ambigüedad, compatibles tanto con la distancia respecto al sistema como con la complicidad con ese mismo statu quo ${ }^{16}$ (circunstancia, por lo demás, aplicable a muchas otras propuestas de arte contemporáneo). Fredric Jameson interpreta esa década como antesala de nuestro presente más inmediato en Periodizing the 60s (1984), época que para él comienza con el proceso de descolonización y el manifiesto teórico de Los condenados de la tierra, de Franz Fanon (196I), y que termina con el agotamiento de ciertas fórmulas políticas y la fragmentación de los movimientos por los derechos civiles en el periodo 1972-1974.

La sensación de desintegración de los proyectos colectivos y de clausura del presente ${ }^{17}$ conduce, como veíamos, bien a la renuncia explícita respecto a la dimensión política, bien a la reintegración de la utopía a parámetros estrictamente literarios o incluso vivenciales-existenciales. De nuevo Ricardo Piglia proporciona una fórmula muy adecuada para condensar esta operación:

Empezó a escribir en la década del 60. ¿Significa eso una marca de origen en su literatura?

Espero que sí. Porque creo que los 60, como se los suele llamar, no son una época sino una posición (Piglia 200I, 95)

"No una época sino una posición": expresión que informa de la espacialización del tiempo a la que aludíamos y también de la metabolización de la política y de la utopía en clave personal, biográfica, estilística (más que genérica, pues, lo estamos viendo, parece que también la hemos desterrado de nuestra imaginación y, en el mejor de los supuestos, la conservamos como un anhelo abstracto o ideal regulativo que no terminamos de concretar en nada que rebase la estricta esfera individual).

Vemos que la ficción de anticipación ligada a los parámetros (post) apocalípticos o de clausura no es un fenómeno de los últimos años, ni tampoco la sensibilidad de la que procede. En este último sentido, hemos hablado de

${ }^{16}$ Véase el magnífico trabajo de Castanedo Alonso (2020).

17 No olvidemos el archicitado diagnóstico de Fukuyama acerca del fin de la historia (FuKUYAMA 1989). 
los ańos sesenta y de la conciencia del final que surge entonces. ${ }^{18}$ Se trata, con todo, de fenómenos que podríamos rastrear mucho antes. La posibilidad de la guerra nuclear y de la eventual destrucción total estuvo muy presente en la conciencia de los que vivieron la Guerra Fría y tuvo su reflejo no solo en los presupuestos, desarrollos e investigaciones militares, sino en la ingeniería, la inversión farmacéutica, la comercialización de búnkeres antinucleares y gran parte de la ciencia-ficción y la cultura popular de la época. Pero incluso antes de que los bombardeos atómicos de Hiroshima y Nagasaki pusiesen de manifiesto esa siniestra posibilidad, ya existía la conciencia del final. En 1940 George Orwell publica En el vientre de la ballena, ensayo que, entre otras cosas, se ocupa de Henry Miller; concretamente analiza Trópico de cáncer, novela publicada en Francia en 1934 y cuya posterior edición inglesa (años sesenta) tuvo que enfrentarse a demandas legales por obscenidad. Una de las cosas que más valora Orwell de Miller es la cuestión que hemos rozado a propósito de Warhol y su relación con la realidad (o con el sistema). En Miller, dice Orwell, encontramos una honestidad y pericia que reproducen la oralidad cotidiana con increíble fidelidad y que entablan una relación de proximidad con la realidad casi inédita en su época:

Con muchos ańos de vida de lumpen a sus espaldas, de hambre, de vagabundeo, de suciedad, de noches al raso, de batallas con los funcionarios de inmigración, de pugnas interminables y picarescas por obtener un poco de dinero, Miller descubre que se lo está pasando muy bien. Le atraen exactamente los mismos aspectos de la vida que a Céline lo han colmado de espanto. Lejos de protestar, acepta. Y la palabra "aceptación" recuerda su verdadera afinidad precisamente con otro norteamericano, con Walt Whitman (ORWELL 1940, 67)

Pero la realidad que acepta y celebra Miller es muy distinta de la que se refleja en Hojas de hierba (I 855); la época de Whitman es una época de prosperidad, esperanza, descubrimiento y libertad, mientras que en el "hoy" de Orwell y de Miller (que en algunos aspectos podría ser el nuestro):

${ }^{18}$ De los años sesenta es también el interesante ensayo de Susan Sontag sobre la cienciaficción, La imaginación del desastre, en el que, entre otras cosas, señala cómo lo esencial de las películas de ciencia-ficción no es la ciencia, sino la catástrofe y la destrucción: la capacidad que tienen de presentar la destrucción, también de las ciudades, de un modo aséptico, neutro, detallado, verosímil y moralmente maniqueo:

Las películas de ciencia-ficción invitan a una concepción desapasionada, estética, de la destrucción y la violencia: una concepción tecnológica. Cosas, objetos, maquinaria, desempeñan un papel protagónico en estas películas. [...] Las cosas, más que los indefensos humanos, son portadoras de valores porque las sentimos, más que la gente, como fuentes de poder. Según las películas de ciencia-ficción, el hombre sin sus artefactos, está desnudo (SonTAG 1965, 277) 
Aceptar la civilización tal cual es prácticamente implica aceptar la decadencia. Ha dejado de ser una actitud denodada y ha pasado a ser pasiva, e incluso "decadente", si es que la palabra aún significa algo.

Pero precisamente porque en cierto sentido es pasivo ante la experiencia, Miller es capaz de acercarse al hombre corriente mucho más que los escritores más decididos. El hombre corriente también es pasivo (Orwell I940, 69)

¿No resulta homologable esa pasividad con la de los ejemplos de la cultura popular más próxima a nosotros en el tiempo que hemos mencionado? Hay una aceptación muy similar en los Sex Pistols, en los Stooges y en el grunge de los ańos noventa, o en propuestas tan elegantes e inclasificables como las de R.E.M., que cantaban al fin del mundo en "It's the end of the world as we know it (and I feel fine)" (I987). Sin salir de la música popular, destacan actualmente el trap o el reggateon, movimientos que, dentro de su pluralidad, evidencian la admisión y celebración de la clausura del mundo, la desaparición de cualquier alternativa y la entrega a la cultura de consumo. ${ }^{19}$ Vemos, por tanto, que las representaciones de la realidad que nos encontramos en el arte y en la cultura hace tiempo que nos transmiten la sensación de que el mundo es más pequeño que nunca y que el presente resulta inamovible:

De ahora en adelante, el hecho que tiene la mayor importancia para el escritor creativo que haya de llegar es que éste no es un mundo de escritores. Esto no significa que no pueda ayudar al alumbramiento de una sociedad nueva, sino tan solo que no podrá tomar parte en ese proceso en calidad de escritor, pues en calidad de escritor es un liberal, y lo que ahora acontece es la destrucción del liberalismo. Parece por tanto probable que, en los años que aún restan de libertad de expresión, cualquier novela que merezca la pena leer siga más o menos las líneas que ha seguido Miller. No me refiero a la técnica ni al material narrativo, sino a los planteamientos que ello implica. Habrá de volver esa actitud pasiva, que será incluso más conscientemente pasiva que antaño. El progreso y la reacción han resultado sendas estafas. En apariencia, no queda sino el quietismo, es decir, el despojamiento de los terrores de la realidad mediante la sumisión a la realidad misma. Adentrémonos en el vientre de la ballena, pues lo estamos, qué duda cabe. Démonos al proceso mundial, dejemos de luchar

19 Por no mencionar el heavy metal que, desde sus orígenes a finales de los sesenta con Black Sabbath, ha abundado en referencias a lo mórbido, a la guerra, a lo claustrofóbico, al colapso mental, a la muerte y a la destrucción, algo que en las siguientes décadas se acentuó con las propuestas dentro del metal más extremo (grindcore, death, doom...) declaradamente apocalípticas, tanto en su estética como en sus letras o en los propios nombres elegidos para sus bandas (Napalm Death, Morbid Angel, Canibal Corpse, Obituary, Entombed...). 
contra todo ello, dejemos de fingir que tenemos aún el control. Es hora de aceptarlo, de resistirlo, de registrarlo. Esa parece ser la fórmula que cualquier novelista coherente ha de aceptar. Una novela basada en líneas más positivas, "constructivas", no emocionalmente espuria, es a día de hoy muy difícil de imaginar siquiera (ORWELL I940, 100)

Antes de Orwell encontramos la misma conciencia de fin de época y de desgaste en Ecos de la era del jazz (I93 I), de Scott Fitzgerald, elegía dedicada a la generación que en los años veinte del pasado siglo disfrutó de un breve pero intenso reinado de placer e irresponsabilidad, de liberación sexual y creatividad artística. ${ }^{20}$ Anterior incluso es el propio Kafka, cuya propuesta narrativa, como comentábamos, resulta tan claustrofóbica como profética. ¿Y no puede ser leído un poema como La tierra baldía (1922) como un epitafio a la tradición y la cultura occidentales, como una voz que surge de entre los muertos y habla para los muertos, para esa multitud zombi que cruza el puente de Londres?

Ciudad Irreal,

bajo la parda niebla de una madrugada de invierno,

la multitud fluía sobre el Puente de Londres, tantos,

jamás pensé que la muerte hubiera deshecho a tantos.

Exhalaban suspiros breves, espaciados,

y cada uno iba con la mirada fija delante de los pies.

(Eliot I 922, vss. 60-5) $)^{21}$

Este ejercicio de arqueología o de reconstrucción de la sensibilidad subyacente al aparente gusto o moda por la ficción distópica o por lo distópico a secas nos podría llevar a remontarnos aún más en el tiempo y a indagar en el nihilismo presente en ciertas obras de Turguénev o Dostoyevski. Y quizá esa cuestión del nihilismo, tan ligada a Nietzsche y a sus consideraciones acerca de

20 "El término jazz, en su progresión hacia la respetabilidad, primero había significado sexo, luego baile, luego música. Se asoció con un estado de excitación nerviosa, no diferente al de las grandes ciudades de detrás de la línea de fuego de una guerra. Para muchos ingleses la guerra todavía sigue activa porque las fuerzas que los amenazaban aún permanecen activas... Por lo tanto, comamos, bebamos y divirtámonos, porque mañana moriremos" (Scott Fitzgerald I93 I, 24).

${ }^{21}$ Traducción de José Luis Palomares, el original dice:

Unreal City,

Under the brown fog of a winter dawn,

A crowd flowed over London Bridge, so many,

I had not thought death had undone so many.

Sighs, short and infrequent, were exhaled,

And each man fixed his eyes before his feet. 
la muerte de Dios y los "últimos hombres", cobre una nueva relevancia como posible clave de lectura del "moderno" gusto por la ficción de anticipación o ciertas formas de realismo. Volvamos a Frye:

En literatura algunas manifestaciones de este movimiento cuasi freudiano, como los beatniks, son movimientos sociales rígidamente convencionalizados, pero lo que para nosotros tiene relevancia es más bien la literatura de protesta, el tema del vagabundeo y la picaresca en Kerouac y Henry Miller, el culto de la violencia en Mailer, la exploración de las drogas y las perversiones, la lucha por una experiencia asocial directa, que es, al parecer, lo que simboliza el interés por el Budismo Zen. El lema de todo esto es el del estornino de Sterne: "no puedo escapar". Expresa la claustrofobia de los impulsos individuales y sexuales prisioneros de la extraña conciencia social que ha creado la civilización. Esto suena como si la literatura contemporánea de protesta fuera intensamente antiutópica, y en muchos aspectos lo es. Sin embargo, en su mayor parte, es un pastoralismo militante o "ludita" que intenta romper el dominio de un estilo de vida que ha reemplazado la perspectiva del cuerpo humano por la perspectiva de sus prolongaciones mecánicas, las prolongaciones del transporte y de la planificación social y de los anuncios, que ahora caen sobre el cuerpo y lo estrangulan, como hicieran las serpientes con Laocoonte (FrYE I982, 80-1)

\section{Consideración final}

Quizá estemos en una época de estertores, en la que los productos de nuestra imaginación reflejan nuestra limitación para hacernos cargo de un tipo de soledad radical, que proviene no solo de la pérdida de vigencia de cualquier dimensión axiológica trascendente —el "desencantamiento del mundo" de Max Weber, la mencionada "muerte de Dios" de Nietzsche-, sino también de la desorientación e indefensión que hemos desarrollado frente a una situación que sustituye a las antiguas deidades, a la Naturaleza o al Destino: la mercantilización absoluta de todos los ámbitos de la experiencia y de la sensibilidad, el anonimato y el carácter implacable y despiadado del modo de producción capitalista. Esto convive, además, con el sometimiento general a las leyes del espectáculo que desestabiliza la frontera entre realidad y ficción. Además de la comentada falta de legitimidad y confianza en proyectos colectivos, la política de partidos no es ajena a los rasgos del postmodernismo cultural. El pastiche, el kitsch y el melodrama parecen haber sustituido a la prudencia y la responsabilidad. La escena política se desarrolla conforme a parámetros dramatúrgicos y el activismo, en numerosas ocasiones, queda 
reducido a determinadas pautas de consumo y a procesos de auto-designación identitaria.

Hemos comprobado que la sensación de estar habitando el final los tiempos es hasta cierto punto recurrente en nuestra historia y que podríamos reconstruir una tradición apocalíptico-milenarista que se remontase, como mínimo, a tiempos bíblicos. La "novedad" del estado de conciencia en el que nos encontramos ahora está ligada al desvanecimiento de la dimensión trascendente, a la cartografía total del mundo, a la experiencia de la ausencia de exterior, a la capitulación global al mismo orden y al desfondamiento de la idea de progreso y de la posibilidad misma de cambio histórico, salvo en su dimensión tecnológica y/o apocalíptica (también en forma de cambio climático). Ello ha dado como resultado un tipo de producción narrativa y cultural que especula con la posibilidad del final del mundo, desenlace en el que intervienen tecnologías que, lejos de servir para emancipar al género humano, lo embrutece y contribuye a su servidumbre; una ficción de anticipación, pues, que gira en torno a la destrucción y al control, que representa a una humanidad dividida, fragmentada en individuos aislados y desencantados que, a lo sumo, establecen entre sí vínculos provisionales supeditados a la misión concreta que han de realizar, que no reflexionan ni actúan pensando en el largo plazo, sino que se limitan a sobrevivir, a adaptarse a un presente puramente espacial. El mundo que esas ficciones plantean se parece a un escenario, a un decorado en el que la dimensión política o está completamente ausente o aparece caracterizada, de modo cínico-satírico, como irrelevante, cuando no directamente como responsable de la catástrofe que el protagonista - o el reducido grupo de protagonistas - ha de afrontar. Este "modo supervivencia" donde lo único que cuenta es la subsistencia inmediata, donde el presente es un absoluto y el fin del mundo un fenómeno banalizado es algo que podemos localizar en relatos, películas, series y videojuegos, y también en lemas -incluso dentro del marco de propuestas teóricas "serias"-, en memes y en la mercadotecnia que explota el "nihilismo pop". No resultaría difícil analizar dichas manifestaciones como actualizaciones insospechadas del Manifiesto futurista (1909) de Marinetti, algo que leyó con perspicacia Walter Benjamin en La obra de arte en la época de su reproductibilidad técnica (I936) con su célebre conclusión:

La humanidad, que hace siglos, en Homero, era un objeto de espectáculo para los dioses olímpicos, se ha convertido ahora en un espectáculo para sí misma. Su autoalienación ha alcanzado tal grado que le permite vivir su propia destrucción como un goce estético de primer orden (BENJAMIN I936, 221) 
En estos días extraños, el lema de Gil Scott-Heron de que la revolución no será televisada adquiere una renovada vigencia. Walter Benjamin apostillaba a propósito de la humanidad que se deleita con el espectáculo de su propia destrucción: "Ésta es la estetización de la política que el fascismo propugna. El comunismo le responde con la politización del arte" (BENJAMin i936, 221). Creemos que es posible escapar a ese hipotético dilema (o estetización de la política o propaganda) mediante una interpretación política del arte y la cultura, llevando a cabo lecturas sintomatológicas que, sin desatender la dimensión literal y temática, se ocupen de los sobreentendidos, de los recursos formales y de las condiciones de inteligibilidad que permiten desentrañar las tensiones y los anhelos de un determinado momento histórico. Y quizá ese ejercicio hermenéutico pueda propiciar reflexiones que sirvan para combatir el conformismo. En este sentido, hemos observado que el presente está caracterizado por el individualismo, el desencanto y la trivialización del fin del mundo. Pero ello no necesariamente significa que las cosas no puedan cambiar, que la única respuesta tenga que ser el cinismo, la complicidad, el egoísmo o la resignación, pues incluso en esos mismos productos culturales de los que hemos hablado, además de la mencionada claustrofobia y cierta necrofilia, también podemos detectar destellos de humor y un deseo de recuperar esa humanidad perdida que recuerdan que no todo está bajo control, que todo programa puede ser saboteado. 


\section{REFERENCIAS BIBLIOGRÁFICAS}

Arjona, D., del Castillo, R., García Aller, M. y Martín, L. 2020, “'La diferencia entre el apocalipsis y la arcadia es la misma que entre twitter e instagram”, Minerva, 34: 27-34.

ATwood, M. 2007, "Everybody is happy now", The Guardian, 17/11/2007: https://www.theguardian.com/books/2007/nov/17/classics.margaretatwood

Ballard, J. G. 2014, The atrocity exhibition, Londres: Fourth State.

Ballard, J. G. 2013, Cuentos completos, Barcelona: RBA.

Beaumont, M. 20I4, "Imagining the End Times: Ideology, the Contemporary Disaster Movie, Contagion”, M. Flisfeder y L. P. Willis (ed.), Žižek and Media Studies, Nueva York: Palgrave Macmillan, 79-89.

Bender, L. (prod.); Tarantino, Q. (dir.) 2009, Inglorious basterds, Estados Unidos-Internacional: Universal Pictures, The Weinstein Company, A Band Apart, Zehnte Babelsberg, Visiona Romantica.

Benjamin, W. I936 [2018], "La obra de arte en la época de su reproductibilidad técnica”, Iluminaciones, Madrid: Taurus, 195-223.

Brooker, C. 20I I-2019, Black Mirror, Reino Unido: Endemol Shine UK.

Carey, J. (ed.) 2000, The Faber Book of Utopias, Eastbourne: Gardners Books.

Castanedo Alonso, M. 2020, Muerte, desastre y accidente. Andy Warhol y el final del sueño americano, tesis doctoral inédita, Universidad de Salamanca.

Curry, A. 2007, "The etymology of "utopia": https://thenextwavefutures.wordpress.com/2007/11/19/the-etymology-of-utopia/

Davies, R. T. 2019, Years and Years, Reino Unido: BBC-HBO.

Eco, U. I984 [2012], "Los mundos de la ciencia-ficción", De los espejos y otros ensayos, Barcelona: Debolsillo, 220-8.

Eliot, T. S. I 922 [2006], La tierra baldía, Madrid: Cátedra.

FAnON, F. I96I [I999], Los condenados de la tierra, Tafalla: Txalaparta.

Fisher, M. 20I6, Realismo capitalista. ¿No hay alternativa?, Buenos Aires: Caja Negra.

Fonda, P., Hayward, W. y Schneider, B. (prod.); Hopper, D. (dir.) i969, Easy Rider, Estados Unidos: Raybert Productions Pando Company Inc.

Funuyama, F. 1989, "The End of History?", The National Interest, 16: 3-18.

Gottrried, H. y Caruso, F. C. (prod.); Lumet, S. (dir.) i 976, Network, Estados Unidos: Metro-Goldwyn-Mayer.

Jameson, F. I979, "Reification and Utopia in Mass Culture", Social Text, 1: 13048.

Jameson, F. I98 I, "Conclusion: The dialectic of Utopia and Ideology", The political unconscious. Narrative as socially symbolic act, Ithaca: Cornell University Press, 280-99. 
Jameson, F. 1984, "Postmodernism, or The Cultural Logic of Late Capitalism", New Left Review, I/146: 52-92.

Jameson, F. I984B [2008], "Periodizing the 60s", The ideologies of theory, Londres y Nueva York: Verso, 483-515.

Jameson, F. 1994, The seeds of time, Nueva York: Columbia University Press.

Jameson, F. 2003A, "Future City", New Left Review, 21: 65-79.

Jameson, F. 2003B, "The End of Temporality", Critical Inquiry: 695-718.

Jameson, F. 2004, "The politics of utopia", New Left Review, 25: 35-54.

Jameson, F. 2005, Archaeologies of the future: the desire called utopia and other science fictions, Londres y Nueva York: Verso.

KafKa, F. 2005 [1922], “Ordené traer mi caballo del establo...", El silencio de las sirenas. Escritos y fragmentos póstumos, Barcelona: DeBolsillo, 257.

Kennedy, B. (prod.); Miller, G. (dir.) i979, Mad Max, Australia: Kennedy Miller Productions.

Kennedy, B. (prod.); Miller, G. (dir.) i98 I, Mad Max 2, Australia: Kennedy Miller Entertainment.

Koselleck, R. 2007A, Crítica y crisis: un ensayo sobre la patogénesis del mundo burgués, Madrid: Trotta.

Koselleck, R. 2007B, Futuro pasado. Para una semántica de los tiempos históricos, Barcelona: Paidós.

Kundera, M. 20 i2, El arte de la novela, Barcelona: Tusquets.

Martorell, F. 2019, Soñar de otro modo. Cómo perdimos la utopía y de qué forma recuperarla, Valencia: La Caja Books.

Miller, G. y Ogilvie, G. (prod.); Miller, G. (dir.) I985, Mad Max Beyond the Thunder dome, Australia: Kennedy Miller Productions.

Mitchell, D., Miller, G. y Voeten P. J. (prod.); Miller, G. (dir.) 20 I 5, Mad Max: Fury Road, Australia: Kennedy Miller Mitchell.

Orwell, G. 1940 [20 10], "En el vientre de la ballena”, El león y el unicornio y otros ensayos, Barcelona: DeBolsillo, 61-104.

Piglia, R. 200 i [201 5], Crítica y ficción, Barcelona: Anagrama.

Piglia, R. 2017, Los diarios de Emilio Renzi. Un día en la vida, Barcelona: Anagrama.

R.E.M. 1987, Document, Culver City: I.R.S. Records.

Rosa, H. 2016, Alienación y aceleración: hacia una teoría crítica de la temporalidad en la modernidad tardía, Madrid: Katz editores.

SÁnchez, J. A. 20 i i, "Utopía e ironía en el contexto de Tomás Moro", Revista de Filosofia, vol. 36, 1: 29-51.

Sánchez Usanos, D. 2010, La experiencia del tiempo en la postmodernidad, tesis doctoral inédita, Universidad Autónoma de Madrid. 
Sánchez Usanos, D. 20I2, "Modernidad, crisis y filosofía", L. Cadahia, y G. Velasco (ed.), Normalidad de la crisis/crisis de la normalidad, Madrid: Katz editores, 45-77.

SÁnchez Usanos, D. 2020, "Experiencia temporal”, P. Arán, A. y Gómez Ponce (ed.), Fredric Jameson: una poética de las formas sociales. Claves conceptuales, Córdoba: Universidad Nacional de Córdoba-Editorial del Centro de Estudios Avanzados, 59-76.

Scott Fitzgerald, F. I93 I [201 2], "Ecos de la era del jazz", El crack-up, Madrid: Capitán Swing, 21-30.

Scott-Heron, G. I971, Pieces of a man, Nueva York: Flying Dutchman Records.

Sex Pistols 1977, Nevermind the bollocks. Here's the Sex Pistols, Londres: Virgin Records.

SontaG. S. 1965 [2008], "La imaginación del desastre", Contra la interpretación y otros ensayos, Barcelona: Debolsillo, 269-90.

Tarantino, Q., Heyman, D. y McIntosh, S. (prod.); Tarantino, Q. (dir.) 2019, Once upon a time in Hollywood, Estados Unidos: Columbia Pictures, Heyday Films, Polybona Films.

The Stooges 1969, The Stooges, Annapolis: Elektra Records.

The Who i97i, Who's next, Londres: Track, Decca.

Thompson, P. y Žıžek, S. (ed.) 2013, The Privatization of Hope: Ernst Bloch and the Future of Utopia, SIC 8 ([sic] Series), Durham: Duke University Press. 
